\title{
Distribution of C-reactive protein and its association with cardiovascular risk factors in a population-based sample of Chinese
}

\author{
Yanfang Zhao ${ }^{\mathrm{a}, 1}$, Rui Wang ${ }^{\mathrm{a}, 1}$, Xiuqiang $\mathrm{Ma}^{\mathrm{a}}$, Xiaoyan Yan $^{\mathrm{a}}$, Zhansai Zhang ${ }^{\mathrm{c}}$, Xiang $\mathrm{He}^{\mathrm{b}, *}$ and \\ Jia $\mathrm{He}^{\mathrm{a}, *}$ \\ ${ }^{a}$ Department of Health Statistics, Second Military Medical University, Shanghai, China \\ ${ }^{\mathrm{b}}$ Health Service Faculty, Second Military Medical University, Shanghai, China \\ ${ }^{\mathrm{c}}$ Institute of Health Inspection, Songjiang District, Shanghai, China
}

\begin{abstract}
C-reactive protein (CRP) levels vary remarkably with ethnic status. Its distribution and correlates should be investigated across diverse populations, and these were limited in a representative Chinese population. We investigated 3133 participants aged 18-80 years in Shanghai, which were sampled using a randomized, stratified, multi-stage sampling method. The distribution of CRP was highly skewed toward a lower level. The median CRP was $0.55 \mathrm{mg} / \mathrm{L}(0.61 \mathrm{mg} / \mathrm{L}$ in males, $0.51 \mathrm{mg} / \mathrm{L}$ in females). Participants living in urban region had higher CRP levels than those in rural region ( $0.67 \mathrm{vs} .0 .46 \mathrm{mg} / \mathrm{L})$. CRP levels showed significant correlation with traditional cardiovascular risk factors, and it was most strongly correlated with body mass index. Multivariate logistic regression analyses indicated that elevated CRP (being in the top 15 percentile of CRP; CRP $\geqslant 2.09 \mathrm{mg} / \mathrm{L}$ ) was significantly associated with obesity, hypertension, diabetes, low high-density lipoprotein cholesterol, high low-density lipoprotein cholesterol, high triglycerides and cardiovascular disease history. In conclusion, the distribution of CRP in adult Chinese was comparable with that of many other Asian populations but different from that of Western populations. Metabolic impairment was associated with elevated CRP, and CRP levels should be interpreted in conjunction with the lipid profile.
\end{abstract}

Keywords: C-reactive protein, cardiovascular, risk factors, Chinese

\section{Introduction}

It was reported that only $50 \%$ of coronary heart disease was accounted for by traditional risk factors such as smoking, hypertension, diabetes and high blood cholesterol level [1]. In fact, up to half of those having their first coronary event didn't have traditional cardiovascular risk factors [2]. These in turn led to many investigations to find other potentially important risk factors which influence cardiovascular disease (CVD)

\footnotetext{
${ }^{1}$ These authors contributed equally to this article.

* Corresponding authors: Jia He, MD, PhD, Department of Health statistics, Second Military Medical University, Shanghai, 200433 China. Tel./Fax: +8621 81871441; E-mail: hejia63@yahoo.com and Xiang He, Health Service Faculty, Second Military Medical University, Shanghai, China.
}

risk. Inflammation is thought to play a very important role in atherogenesis [3]. C-reactive protein (CRP), an acute-phase reactant and sensitive marker of subclinical inflammation, is the most extensively studied biomarker.

Previous studies have shown that high CRP is strongly associated with various risk factors of CVD [4,5], and it was advocated to measure CRP to assess CVD risk [6]. The guidelines on CRP testing from American Heart Association/Centers for Disease Control and Prevention (AHA/CDC) suggested that measurement of CRP to improve assessment of people at intermediate coronary heart disease risk, and the CRP levels were proposed to be $>3.0 \mathrm{mg} / \mathrm{L}$ as high vascular risk [7]. However, this cutoff was based mainly on data from Western populations. It is well known that CRP levels 
vary remarkably with ethnic status [8,9]. The distribution of CRP in Asian populations seemed different from that of Western populations [10]. Therefore, using uniform CRP cutoff points to define vascular risk is likely not appropriate across diverse populations. So, before its use in risk screening in different populations, the distribution and correlates of CRP in the general population should be investigated. However, such information was limited in Chinese. In this study, we aimed to evaluate the distribution of CRP and its association with cardiovascular risk factors in a representative Chinese population, including young, middle-aged and older adults.

\section{Methods}

\subsection{Sample}

A representative sample of the Shanghai population of both genders aged 18-80 years was selected, using a randomized, stratified, multiple-stage sampling method. Eligibility criteria were based on age, and mental and physical ability to participate in the survey. In the first stage, we randomly sampled one rural region (Baoshan District) and one urban region (Hongkou District) from 18 districts in Shanghai. In the second stage, we randomly sampled two villages from Baoshan District and two street offices from Hongkou District. In the third stage, several residential areas were sampled. Then, 3600 people (1800 from Baoshan and Hongkou Districts, respectively) were randomly sampled, stratified by gender and age in proportion to the number of inhabitants recorded by the 2000 Shanghai Population Census.

The study was approved by the committee for medical ethics of the Second Military Medical University (SMMU), and an informed written consent was obtained from every participant. From April 2007 to February 2008, a total of 3153 participants (1402 males and 1751 females) completed the survey, and the overall response rate was $87.6 \%$. Participants $(\mathrm{N}=20)$ with missing records of the CRP values were deleted from the analyses, and 3133 participants were included in the analyses.

\subsection{Data collection}

Every participant was asked to complete a comprehensive health and lifestyle questionnaire and to provide a collection of fasting blood samples. General information was collected on age, gender, residential region, marital status, education level, current job, family monthly income, height, weight, smoking status, alcohol consumption, frequency of recreational exercise and medical history (current and previous medical problems and related treatment). Body mass index (BMI) was calculated as weight $(\mathrm{kg}) /$ height $(\mathrm{m})^{2}$. In order to analyze the reliability of the self-reported values of BMI, $20 \%$ of the sample was randomly selected for height and weight measurement. Height was measured using a stadiometer, and weight was measured with participants in light underclothes.

Questionnaires were self-administered, and explanation and supervision were provided by trained interviewers where necessary. The interviewers were social workers at the survey sites, who were trained by supervisors who were professionals from the Department of Health Statistics (DoHS) of the SMMU. Supervisors supervised the work of the interviewers and examined questionnaires for any errors to ensure the quality of the survey. A valid questionnaire was the one that had been audited and signed by a supervisor.

An informed written consent for blood sampling was also obtained from every participant before blood sampling. Participants were required to fast for at least 10 hours. Venous blood samples were collected from each participant, and the samples were refrigerated immediately in an ice box and the box was shipped to Changhai hospital which belongs to the SMMU after blood collections. All samples were tested immediately after they were transferred to the hospital clinical laboratory without storing. Total cholesterol, lowdensity lipoprotein cholesterol (LDL-C), high-density lipoprotein cholesterol (HDL-C), triglycerides and glucose were measured enzymatically using an automatic chemical analyzer (Hitachi 7600-20, Japan), and plasma CRP were measured with immunonephelometry on a special protein analyzer (Beckman, US). The lower limit of detection was $0.151 \mathrm{mg} / \mathrm{L}$. Undetectable CRP values were recorded as $<0.151 \mathrm{mg} / \mathrm{L}$. The intra-assay and inter -assay coefficients of variation were $3.6 \%$ and $4.3 \%$, respectively.

\subsection{Definition of cardiovascular risk factors}

We used cutoff values from the third National Health and Nutrition Examination Survey (NHANES III) for defining normal, borderline, or abnormal cardiovascular risk factors [5]. They included diabetes mellitus (normal, $<5.55 \mathrm{mmol} / \mathrm{L}[<100 \mathrm{mg} / \mathrm{dL}]$; pre-diabetes mellitus, fasting glucose 5.56 to $6.94 \mathrm{mmol} / \mathrm{L}$ [100 to 
$125 \mathrm{mg} / \mathrm{dL}]$; and diabetes mellitus, $\geqslant 6.99 \mathrm{mmol} / \mathrm{L}$ $[\geqslant 126 \mathrm{mg} / \mathrm{dL}]$ or previously diagnosed diabetes); blood pressure (normal, having no hypertension history; hypertension, having hypertension diagnosed by physicians); total cholesterol levels (normal, < $5.18 \mathrm{mmol} / \mathrm{L}[<200 \mathrm{mg} / \mathrm{dL}]$; borderline high, 5.18 to $6.19 \mathrm{mmol} / \mathrm{L}$ [200 to $239 \mathrm{mg} / \mathrm{dL}$; and high, $\geqslant$ $6.22 \mathrm{mmol} / \mathrm{L}[\geqslant 240 \mathrm{mg} / \mathrm{dL}]$ ); triglyceride levels (nor$\mathrm{mal},<1.70 \mathrm{mmol} / \mathrm{L}[<150 \mathrm{mg} / \mathrm{dL}]$; borderline high, 1.70 to $2.25 \mathrm{mmol} / \mathrm{L}$ [150 to $199 \mathrm{mg} / \mathrm{dL}$ ]; and high, $\geqslant 2.26 \mathrm{mmol} / \mathrm{L}[\geqslant 200 \mathrm{mg} / \mathrm{dL}])$; and HDL$\mathrm{C}$ values (normal, $\geqslant 1.04 \mathrm{mmol} / \mathrm{L}[\geqslant 40 \mathrm{mg} / \mathrm{dL}]$ in males and $\geqslant 1.30 \mathrm{mmol} / \mathrm{L}[\geqslant 50 \mathrm{mg} / \mathrm{dL}]$ in females; low, $<1.04 \mathrm{mmol} / \mathrm{L}[<40 \mathrm{mg} / \mathrm{dL}]$ in males and $<$ $1.30 \mathrm{mmol} / \mathrm{L}[<50 \mathrm{mg} / \mathrm{dL}]$ in females); LDL-C (nor$\mathrm{mal},<3.37 \mathrm{mmol} / \mathrm{L}[130 \mathrm{mg} / \mathrm{dL}] ;$ borderline high, 3.37 to $4.12 \mathrm{mmol} / \mathrm{L}[130$ to $159 \mathrm{mg} / \mathrm{dL}]$; and high, $\geqslant 4.14 \mathrm{mmol} / \mathrm{L}[\geqslant 160 \mathrm{mg} / \mathrm{dL}]$ ) [11]. BMI was defined according to the Chinese criterion (normal, < $24 \mathrm{~kg} / \mathrm{m}^{2}$; overweight, 24 to $28 \mathrm{~kg} / \mathrm{m}^{2}$; and obese, $\geqslant$ $28 \mathrm{~kg} / \mathrm{m}^{2}$ ) [12].

Smoking status was classified as never, former and current. Alcohol consumption was grouped into never, $<4$ times/month, at least one time/week and daily. Physical activity was graded according to frequency into 4 categories as sedentary (never), light activity (less than 4 times per month), moderate activity (at least 1 time per week) and vigorous activity (at least 1 time per day). Marital status was categorized into 4 groups (married, unmarried, divorced or separated, widowed). Family monthly income was defined as " $<$ 1999 Yuan" and " $\geqslant 1999$ Yuan". Current job was defined as "manual worker" and "office worker". A history of CVD was defined as diagnosis with coronary heart disease, myocardial infarction, angina pectoris, cerebrovascular disorder, and so on by physicians.

\subsection{Statistical analysis}

Data were double entered by two independent professional data processors in the DoHS using software Epidata 3.1. Both manual checking and computer checking were conducted to find discrepancies. Student $t$ test for continuous variables and Chi-square test or Cochran-Mantel-Haenszel statistics for categorical variables were applied for the comparison between males and females. The reliability of BMI was assessed by the differences between self-reported and measured values using a paired-sample $t$ test. The median level of CRP was tested with Wilcoxon rank sum test when comparing between strata. Categorical forms of the values were performed in age- and multivariateadjusted logistic regression analyses. CRP as the dependent variable was dichotomized at the top 15 th percentile $(2.09 \mathrm{mg} / \mathrm{L})$, and CRP values more than the top 15 th percentile values were defined as elevated CRP. The odds ratios (ORs) and 95\% confidence interval (CI) for elevated CRP were calculated. Data management and statistical analysis were performed with the SAS statistical package version 9.1.3 (SAS Institute, Cary, North Carolina). Statistical tests were 2-sided, and a $p$ value $<0.05$ was considered statistically significant.

\section{Results}

Characteristics of the 3133 participants (1393 males and 1740 females) are shown in Table 1 . The mean age was 47.8 years (47.8 for males and 47.8 for females). Compared with the females, the males had higher BMI and triglycerides, lower HDL-C and higher prevalence of hypertension and diabetes (all $p<0.05$ ). More males smoked and drunk. About $5.0 \%$ of the participants (158/3133) reported having history of CVD, and 136 participants with history of CVD reported that they had received treatments. A total of 244 participants reported that they had diabetes or were diagnosed as diabetes. Among them, 128 participants received treatments. A total of 650 had hypertension, and 597 of them received treatments. In total, 696 were treated as someone may receive one or more treatments. The absolute differences between the self-reported and measured values of BMI ranged from 0.0 to $4.5 \mathrm{~kg} / \mathrm{m}^{2}$. The paired-sample $t$ test indicated that the difference was not statistically significant ( $p=0.6364$ ).

Table 2 presents the distribution of CRP by gender, age, region, BMI, blood pressure, glucose, total cholesterol, HDL-C, LDL-C, triglycerides, smoking and alcohol consumption categories. Median CRP was $0.55 \mathrm{mg} / \mathrm{L}$ for all the participants $(0.61 \mathrm{mg} / \mathrm{L}$ in males and $0.51 \mathrm{mg} / \mathrm{L}$ in females). The distribution of CRP for both males and females were highly skewed toward a lower level. Among the participants, 165 (5.3\%) had a CRP level $<0.15 \mathrm{mg} / \mathrm{L}$, and more than $65 \%$ of the participants $(\mathrm{N}=2108)$ had a CRP level $<1 \mathrm{mg} / \mathrm{L}$. The percentages of those with CRP levels $>3 \mathrm{mg} / \mathrm{L}$ based on AHA/CDC defined risk categories were $10.2 \%(N=318)$ in the whole population (11.1\% in males, $9.4 \%$ in females). Only $1.3 \%$ of the participants $(\mathrm{N}=42)$ had $\mathrm{CRP}>10 \mathrm{mg} / \mathrm{L}$. CRP levels increased with age, though the CRP levels were a little lower in age of 30-39 years than those of younger 
Table 1

Characteristics of the participants by gender*

\begin{tabular}{|c|c|c|c|c|}
\hline Characteristics & Total $(N=3133)$ & Male $(N=1393)$ & Female $(N=1740)$ & $\mathrm{P}$ value $^{\dagger}$ \\
\hline Mean age (years) & $47.8 \pm 14.1$ & $47.8 \pm 14.1$ & $47.8 \pm 14.1$ & 0.9615 \\
\hline $\mathrm{BMI}\left(\mathrm{kg} / \mathrm{m}^{2}\right)$ & $23.2 \pm 3.3$ & $23.7 \pm 3.3$ & $22.8 \pm 3.3$ & $<0.0001$ \\
\hline Total cholesterol (mmol/L) & $4.9 \pm 1.2$ & $4.9 \pm 1.5$ & $5.0 \pm 1.0$ & 0.0886 \\
\hline $\mathrm{LDL}-\mathrm{C}(\mathrm{mmol} / \mathrm{L})$ & $3.2 \pm 0.9$ & $3.2 \pm 0.8$ & $3.2 \pm 0.9$ & 0.5337 \\
\hline $\mathrm{HDL}-\mathrm{C}(\mathrm{mmol} / \mathrm{L})$ & $1.4 \pm 0.3$ & $1.3 \pm 0.3$ & $1.5 \pm 0.3$ & $<0.0001$ \\
\hline Triglycerides (mmol/L) & $1.5 \pm 1.2$ & $1.7 \pm 1.4$ & $1.3 \pm 1.0$ & $<0.0001$ \\
\hline Serum glucose $(\mathrm{mmol} / \mathrm{L})$ & $5.3 \pm 1.4$ & $5.3 \pm 1.5$ & $5.3 \pm 1.3$ & 0.6937 \\
\hline Hypertension (\%) & $650(20.8)$ & $313(22.5)$ & 337 (19.4) & 0.0334 \\
\hline Marital status (\%) & & & & $<0.0001$ \\
\hline Married & $2678(85.5)$ & $1187(85.3)$ & $1492(85.8)$ & \\
\hline Unmarried & $288(9.2)$ & $166(11.9)$ & $122(7.0)$ & \\
\hline Divorced or separated & $46(1.5)$ & $18(1.3)$ & $28(1.6)$ & \\
\hline Widowed & $119(3.8)$ & $21(1.5)$ & $98(5.6)$ & \\
\hline Family monthly income (\%) & & & & 0.3234 \\
\hline Less than 1999 Yuan & $1247(39.8)$ & $541(38.8)$ & $706(40.6)$ & \\
\hline More than 1999 Yuan & $1886(60.2)$ & $852(61.2)$ & $1034(59.4)$ & \\
\hline Current job & & & & 0.0002 \\
\hline Manual worker & $2311(73.8)$ & $982(70.5)$ & $1329(76.4)$ & \\
\hline Office worker & $822(26.2)$ & $411(29.5)$ & $411(23.6)$ & \\
\hline Glucose category (\%) & & & & 0.0024 \\
\hline Normal & $2304(73.5)$ & $1025(73.6)$ & $1279(73.5)$ & \\
\hline Prediabetes & $585(18.7)$ & $237(17.0)$ & $348(20.0)$ & \\
\hline Diabetes & $244(7.8)$ & $131(9.4)$ & $113(6.5)$ & \\
\hline Smoking status (\%) & & & & $<0.0001$ \\
\hline Never & $2132(68.1)$ & $434(31.2)$ & $1698(97.6)$ & \\
\hline Former & $81(2.6)$ & $79(5.7)$ & $2(0.1)$ & \\
\hline Current & $920(29.4)$ & $880(63.2)$ & $40(2.3)$ & \\
\hline Alcohol consumption $(\%)$ & & & & $<0.0001$ \\
\hline Never & $2560(80.0)$ & $800(57.4)$ & $1760(98.1)$ & \\
\hline$<4$ times/month & $127(4.1)$ & $122(8.8)$ & $5(8.8)$ & \\
\hline One time/week & $170(5.4)$ & $156(11.2)$ & $14(0.8)$ & \\
\hline Daily & $330(10.5)$ & $315(22.6)$ & $15(0.9)$ & \\
\hline Physical activity (\%) & & & & 0.7381 \\
\hline Sedentary & $577(18.4)$ & $261(18.8)$ & $316(18.2)$ & \\
\hline Light activity & $144(4.6)$ & $68(4.9)$ & $76(4.4)$ & \\
\hline Moderate activity & $327(10.4)$ & $138(9.9)$ & $189(10.9)$ & \\
\hline Vigorous activity & $2083(66.5)$ & $925(66.5)$ & $1158(66.6)$ & \\
\hline CVD history (\%) & & & & 0.3448 \\
\hline No & $2975(95.0)$ & $1317(94.5)$ & $1658(95.3)$ & \\
\hline Yes & $158(5.0)$ & $76(5.5)$ & $82(4.7)$ & \\
\hline
\end{tabular}

BMI = body mass index; CVD = Cardiovascular disease; HDL-C = high-density lipoprotein cholesterol; LDL-C $=$ low-density lipoprotein cholesterol.

${ }^{*}$ Values are arithmetic means $\pm \mathrm{SD}$ unless indicated otherwise. ${ }^{\dagger} \mathrm{P}$ value was calculated by comparing men with women

group. The median CRP of participants in urban and rural areas was $0.67 \mathrm{mg} / \mathrm{L}$ and $0.46 \mathrm{mg} / \mathrm{L}$, respectively. Those who had higher BMI, hypertension, higher glucose, higher total cholesterol, higher LDL-C, higher triglycerides and lower HDL-C had significantly higher CRP levels (all $p<0.05$ ). There was significant difference of CRP levels among the categories of smoking $(p=0.0066)$. However, the difference was not significant ( $p=0.1392$ ) when females were excluded from the analysis. We didn't find a difference in CRP levels among the different alcohol consumption categories $(p=0.2397)$, even only in males $(p=0.1048)$.
When the 696 participants with treatments for CVD or hypertension or diabetes were excluded, the median CRP was $0.49 \mathrm{mg} / \mathrm{L}$ which was not increased. Furthermore, when the participants with history of CVD, hypertension, diabetes or with CRP $>10 \mathrm{mg} / \mathrm{L}$ were all excluded from the analyses $(n=2288)$, the CRP levels became lower with median CRP was $0.47 \mathrm{mg} / \mathrm{L}$. The median levels of CRP decreased slightly in females $(0.43 \mathrm{mg} / \mathrm{L})$ and males $(0.52 \mathrm{mg} / \mathrm{L})$. Medians of CRP for age groups 18 to 29,30 to 39,40 to 49,50 to 59,60 to 69,70 to 80 years were $0.41,0.37,0.45,0.55,0.65$ and $0.88 \mathrm{mg} / \mathrm{L}$. 
Table 2

Distribution of C-reactive protein levels $(\mathrm{mg} / \mathrm{L})$ among the participants aged 18-80 years in Shanghai, China $(N=3133)$

\begin{tabular}{|c|c|c|c|c|c|c|c|c|c|c|}
\hline \multirow[t]{2}{*}{ Variable } & \multirow[b]{2}{*}{$\mathrm{n}$} & \multicolumn{9}{|c|}{ Percentile } \\
\hline & & 5 th & 10th & 25 th & 33.3th & 50th & 66.7th & 75th & 90th & 95th \\
\hline Total & 3133 & 0.15 & 0.16 & 0.26 & 0.34 & 0.55 & 0.95 & 1.34 & 3.04 & 4.74 \\
\hline \multicolumn{11}{|l|}{ Gender } \\
\hline Female & 1740 & 0.15 & 0.16 & 0.22 & 0.31 & 0.51 & 0.84 & 1.22 & 2.81 & 4.23 \\
\hline Male & 1393 & 0.16 & 0.16 & 0.30 & 0.38 & 0.61 & 1.09 & 1.50 & 3.21 & 5.14 \\
\hline \multicolumn{11}{|l|}{ Age } \\
\hline $18-29$ & 347 & 0.15 & 0.16 & 0.17 & 0.23 & 0.42 & 0.72 & 1.03 & 2.77 & 4.44 \\
\hline 30-39 & 493 & 0.15 & 0.16 & 0.18 & 0.24 & 0.40 & 0.68 & 1.02 & 2.23 & 4.06 \\
\hline $40-49$ & 1061 & 0.15 & 0.16 & 0.25 & 0.32 & 0.49 & 0.82 & 1.13 & 2.39 & 3.94 \\
\hline $50-59$ & 593 & 0.16 & 0.17 & 0.31 & 0.42 & 0.64 & 1.14 & 1.50 & 3.07 & 4.37 \\
\hline $60-69$ & 378 & 0.16 & 0.19 & 0.35 & 0.50 & 0.82 & 1.32 & 1.88 & 4.20 & 5.71 \\
\hline $70-80$ & 261 & 0.16 & 0.22 & 0.45 & 0.57 & 0.98 & 1.55 & 1.98 & 4.31 & 5.38 \\
\hline \multicolumn{11}{|l|}{ Region } \\
\hline Urban & 1568 & 0.16 & 0.16 & 0.32 & 0.42 & 0.67 & 1.14 & 1.53 & 3.56 & 5.71 \\
\hline Rural & 1565 & 0.15 & 0.16 & 0.21 & 0.28 & 0.46 & 0.74 & 1.11 & 2.40 & 4.02 \\
\hline \multicolumn{11}{|l|}{ BMI } \\
\hline Normal & 1906 & 0.15 & 0.16 & 0.19 & 0.26 & 0.43 & 0.67 & 0.93 & 2.22 & 4.06 \\
\hline Overweight & 970 & 0.16 & 0.21 & 0.36 & 0.47 & 0.75 & 1.30 & 1.64 & 3.42 & 5.38 \\
\hline Obese & 253 & 0.25 & 0.34 & 0.65 & 0.91 & 1.49 & 2.10 & 2.73 & 4.62 & 5.98 \\
\hline \multicolumn{11}{|l|}{ Blood pressure } \\
\hline Normal & 2483 & 0.15 & 0.16 & 0.23 & 0.31 & 0.49 & 0.81 & 1.14 & 2.45 & 4.35 \\
\hline Hypertension & 650 & 0.16 & 0.21 & 0.42 & 0.55 & 0.92 & 1.56 & 2.12 & 3.95 & 5.56 \\
\hline \multicolumn{11}{|l|}{ Glucose } \\
\hline Normal & 2304 & 0.15 & 0.16 & 0.24 & 0.31 & 0.50 & 0.84 & 1.19 & 2.58 & 4.20 \\
\hline Pre-diabetes & 585 & 0.15 & 0.16 & 0.30 & 0.42 & 0.69 & 1.16 & 1.57 & 3.31 & 5.21 \\
\hline Diabetes & 244 & 0.16 & 0.18 & 0.41 & 0.59 & 0.99 & 1.70 & 2.65 & 5.08 & 7.70 \\
\hline \multicolumn{11}{|l|}{ Total cholesterol } \\
\hline Normal & 1998 & 0.15 & 0.16 & 0.21 & 0.29 & 0.47 & 0.79 & 1.11 & 2.75 & 4.44 \\
\hline Borderline & 860 & 0.16 & 0.17 & 0.31 & 0.40 & 0.68 & 1.17 & 1.57 & 3.30 & 5.28 \\
\hline High & 275 & 0.16 & 0.26 & 0.50 & 0.61 & 0.91 & 1.52 & 1.82 & 3.50 & 4.88 \\
\hline \multicolumn{11}{|l|}{ HDL-C } \\
\hline Normal & 2268 & 0.15 & 0.16 & 0.24 & 0.32 & 0.52 & 0.89 & 1.23 & 2.87 & 4.44 \\
\hline Low & 865 & 0.16 & 0.16 & 0.31 & 0.39 & 0.65 & 1.19 & 1.56 & 3.57 & 5.30 \\
\hline \multicolumn{11}{|l|}{ LDL-C } \\
\hline Normal & 1907 & 0.15 & 0.16 & 0.21 & 0.28 & 0.47 & 0.77 & 1.09 & 2.69 & 4.38 \\
\hline Borderline & 853 & 0.16 & 0.17 & 0.31 & 0.40 & 0.66 & 1.15 & 1.54 & 3.16 & 5.00 \\
\hline High & 373 & 0.16 & 0.24 & 0.48 & 0.60 & 0.87 & 1.49 & 1.92 & 3.71 & 5.71 \\
\hline \multicolumn{11}{|l|}{ Triglycerides } \\
\hline Normal & 2319 & 0.15 & 0.16 & 0.21 & 0.28 & 0.46 & 0.74 & 1.07 & 2.51 & 4.41 \\
\hline Borderline & 381 & 0.18 & 0.23 & 0.43 & 0.55 & 0.88 & 1.36 & 1.64 & 3.75 & 5.52 \\
\hline High & 433 & 0.17 & 0.28 & 0.52 & 0.68 & 1.10 & 1.74 & 2.22 & 3.58 & 5.59 \\
\hline \multicolumn{11}{|l|}{ Smoking } \\
\hline Never & 2132 & 0.15 & 0.16 & 0.24 & 0.32 & 0.54 & 0.90 & 1.31 & 2.96 & 4.61 \\
\hline Former & 81 & 0.16 & 0.18 & 0.37 & 0.45 & 0.69 & 1.07 & 1.36 & 2.73 & 5.03 \\
\hline Current & 920 & 0.16 & 0.16 & 0.29 & 0.36 & 0.57 & 1.04 & 1.49 & 3.11 & 4.87 \\
\hline \multicolumn{11}{|c|}{ Alcohol consumption } \\
\hline Never & 2505 & 0.15 & 0.16 & 0.25 & 0.34 & 0.55 & 0.94 & 1.33 & 3.01 & 4.62 \\
\hline$<4$ times/month & 127 & 0.15 & 0.15 & 0.24 & 0.34 & 0.56 & 0.93 & 1.22 & 3.10 & 4.72 \\
\hline One time/week & 170 & 0.16 & 0.16 & 0.24 & 0.33 & 0.51 & 0.92 & 1.33 & 3.33 & 5.00 \\
\hline Daily & 330 & 0.16 & 0.17 & 0.29 & 0.38 & 0.63 & 1.05 & 1.57 & 3.20 & 5.03 \\
\hline
\end{tabular}

$\mathrm{BMI}=$ body mass index; HDL-C = high-density lipoprotein cholesterol; LDL-C = low-density lipoprotein cholesterol.

Prevalence of elevated CRP (CRP $\geqslant 2.09 \mathrm{mg} / \mathrm{L}$ ) in the participants based on potential risk factors is shown in Table 3. The prevalence was higher in males than in females (16.8\% vs. $13.7 \%)$; however, this association was not significant in the multivariate analysis
(OR: 1.2 [95\%CI: 0.9-1.7]). Participants who lived in rural region had a lower prevalence of elevated CRP than those in urban region (12.2\% vs. $18.0 \%)$, and the difference was confirmed in multivariate-adjusted logistic regression analysis (OR: 0.7 [95\%CI: $0.5-0.9]$ ]). 
Table 3

Age- and multivariate-adjusted odds ratios (ORs) for elevated CRP*

\begin{tabular}{|c|c|c|c|}
\hline Variable & $\begin{array}{c}\text { Prevalence of elevated CRP } \\
\mathrm{N}(\%) \\
\end{array}$ & $\begin{array}{l}\text { Age- adjusted } \\
\text { OR }(95 \% \mathrm{CI})\end{array}$ & $\begin{array}{c}\text { Multivariate- adjusted }^{\dagger} \\
\text { OR }(95 \% \text { CI }) \\
\end{array}$ \\
\hline $\begin{array}{l}\text { Gender } \\
\text { Female }(N=1740) \\
\text { Male }(N=1393)\end{array}$ & $\begin{array}{l}13.7 \\
16.8\end{array}$ & $\begin{array}{c}1.0 \\
1.3(1.1-1.6)\end{array}$ & $\begin{array}{c}1.0 \\
1.2(0.9-1.7)\end{array}$ \\
\hline $\begin{array}{l}\text { Region } \\
\text { Urban }(N=1568) \\
\text { Rural }(N=1565)\end{array}$ & $\begin{array}{l}18.0 \\
12.2\end{array}$ & $\begin{array}{c}1.0 \\
0.7(0.5-0.8)\end{array}$ & $\begin{array}{c}1.0 \\
0.7(0.5-0.9)\end{array}$ \\
\hline $\begin{array}{l}\text { BMI } \\
\text { Normal }(N=1906) \\
\text { Overweight }(N=970) \\
\text { Obese }(N=253)\end{array}$ & $\begin{array}{l}10.8 \\
18.7 \\
34.0\end{array}$ & $\begin{array}{c}1.0 \\
1.8(1.5-2.3) \\
4.3(3.2-5.8)\end{array}$ & $\begin{array}{c}1.0 \\
1.1(1.2-1.9) \\
3.2(2.3-4.5)\end{array}$ \\
\hline $\begin{array}{l}\text { Hypertension } \\
\text { No }(N=2483) \\
\text { Yes }(N=650)\end{array}$ & $\begin{array}{l}12.5 \\
25.1\end{array}$ & $\begin{array}{c}1.0 \\
2.0(1.6-2.5)\end{array}$ & $\begin{array}{c}1.0 \\
1.4(1.1-1.8)\end{array}$ \\
\hline $\begin{array}{l}\text { Glucose } \\
\text { Normal }(N=2304) \\
\text { Pre-diabetes }(N=585) \\
\text { Diabetes }(N=244)\end{array}$ & $\begin{array}{l}12.9 \\
18.1 \\
28.7\end{array}$ & $\begin{array}{c}1.0 \\
1.4(1.8-1.8) \\
2.2(1.6-3.1)\end{array}$ & $\begin{array}{c}1.0 \\
1.3(1.0-1.6) \\
1.7(1.2-2.4)\end{array}$ \\
\hline $\begin{array}{l}\text { Total cholesterol } \\
\text { Normal }(N=1998) \\
\text { Borderline }(N=860) \\
\text { High }(N=275)\end{array}$ & $\begin{array}{l}13.0 \\
18.3 \\
20.7\end{array}$ & $\begin{array}{c}1.0 \\
1.3(1.8-1.7) \\
1.4(1.0-2.0)\end{array}$ & $\begin{array}{c}1.0 \\
0.9(0.6-1.2) \\
0.6(0.4-1.1)\end{array}$ \\
\hline $\begin{array}{l}\text { HDL-C } \\
\text { Normal }(N=2268) \\
\text { Low }(N=865)\end{array}$ & $\begin{array}{l}13.6 \\
19.2\end{array}$ & $\begin{array}{c}1.0 \\
1.5(1.2-1.8)\end{array}$ & $\begin{array}{c}1.0 \\
1.4(1.1-1.8)\end{array}$ \\
\hline $\begin{array}{l}\text { LDL-C } \\
\text { Normal }(N=1907) \\
\text { Borderline }(N=853) \\
\text { High }(N=373)\end{array}$ & $\begin{array}{l}12.7 \\
16.8 \\
23.6\end{array}$ & $\begin{array}{c}1.0 \\
1.3(1.0-1.6) \\
1.8(1.4-2.4)\end{array}$ & $\begin{array}{c}1.0 \\
1.2(0.9-1.7) \\
2.0(1.3-3.6)\end{array}$ \\
\hline $\begin{array}{l}\text { Triglycerides } \\
\text { Normal }(N=2319) \\
\text { Borderline }(N=381) \\
\text { High }(N=433)\end{array}$ & $\begin{array}{l}12.3 \\
19.2 \\
26.8\end{array}$ & $\begin{array}{c}1.0 \\
1.6(1.2-2.2) \\
2.5(1.9-3.2)\end{array}$ & $\begin{array}{c}1.0 \\
1.1(0.8-1.5) \\
1.7(1.3-2.2)\end{array}$ \\
\hline $\begin{array}{l}\text { Smoking } \\
\text { Never }(N=2132) \\
\text { Former }(N=81) \\
\text { Current }(N=920)\end{array}$ & $\begin{array}{l}14.6 \\
16.1 \\
16.2\end{array}$ & $\begin{array}{c}1.0 \\
0.9(0.5-1.7) \\
1.2(0.9-1.5)\end{array}$ & $\begin{array}{c}1.0 \\
0.6(0.3-1.2) \\
1.1(0.8-1.5)\end{array}$ \\
\hline $\begin{array}{l}\text { Alcohol consumption } \\
\text { Never }(N=2505) \\
<4 \text { times/month }(N=127) \\
\text { One time/week }(N=170) \\
\text { Daily }(N=330)\end{array}$ & $\begin{array}{l}15.0 \\
13.4 \\
15.9 \\
16.1\end{array}$ & $\begin{array}{c}1.0 \\
0.9(0.6-1.6) \\
1.1(0.7-1.7) \\
1.0(0.7-1.4)\end{array}$ & $\begin{array}{c}1.0 \\
0.7(0.4-1.3) \\
0.9(0.6-1.5) \\
0.9(0.6-1.3)\end{array}$ \\
\hline $\begin{array}{l}\text { CVD history } \\
\text { No }(n=2975) \\
\text { Yes }(n=158)\end{array}$ & $\begin{array}{l}14.4 \\
29.1\end{array}$ & $\begin{array}{c}1.0 \\
1.8(1.3-2.7)\end{array}$ & $\begin{array}{c}1.0 \\
1.5(1.0-2.3)\end{array}$ \\
\hline
\end{tabular}

The prevalence of elevated CRP increased with increasing BMI, and BMI was also positively associated with CRP in the multivariate analysis (Table 3). Participants with hypertension had a higher prevalence of elevated CRP than those without (multivariate OR: 1.4 [95\%CI:
1.1-1.8]). Participants with diabetes were more likely to have elevated CRP than those with normal glucose (multivariate OR: 1.7 [95\%CI: 1.2-2.4]). People with higher total cholesterol showed an increased likehood of reporting elevated CRP, but after multivariate ad- 
Table 4

Differences in medians of CRP levels among different studies of Chinese

\begin{tabular}{lcccc}
\hline First author & Gender & Age (years) & N & CRP (mg/L) \\
\hline Our study & Male & 47.8 & 1740 & 0.61 \\
& Female & 47.8 & 1393 & 0.51 \\
B. Yuan [15] & Male & $21.0-66.0$ & 157 & 0.80 \\
& Female & $21.0-66.0$ & 365 & 0.70 \\
Q. Dong [16] & Male & $22.0-83.0$ & 579 & 0.89 \\
& Female & $22.0-83.0$ & 162 & 0.58 \\
X. Ye [17] & Male & 58.8 & 1458 & 0.67 \\
& Female & 58.5 & 1831 & 0.69 \\
J. Sun [18] & Male & $45.0-74.0$ & 702 & 1.00 \\
& Female & $45.0-74.0$ & 842 & 1.00 \\
Y. Bao [19] & Male & 53.2 & 2379 & 1.28 \\
& Female & 52.6 & 3123 & 1.29 \\
H. Sun [20] & Both & $<50.0$ & 70 & 0.72 \\
& Both & $>50.0$ & 170 & 1.09 \\
S. He [21] & Both & $20.0-70.0$ & 506 & 0.45 \\
\hline
\end{tabular}

CRP $=$ C-reactive protein.

justment, the relationship was not significant. HDL-C had a slight effect on the prevalence of elevated CRP, with participants with low HDL-C being significantly more likely to have elevated CRP than those with normal HDL-C (multivariate OR: 1.4 [95\%CI: 1.1-1.8]). LDL-C and triglycerides were also significantly associated with elevated CRP, even after adjusting for all the other factors. The prevalence of elevated CRP was 2.0-fold higher in the participants with cardiovascular disease history than those without (29.1\% vs. $14.4 \%)$. Those participants with cardiovascular disease history had an OR of 1.8 (95\%CI: 1.3-2.7) controlling age compared with those without, and the value decreased slightly, but the association was still significant after controlling all the other factors. No significant associations were detected between elevated CRP and smoking and alcohol consumption.

\section{Discussion}

Recently, a prospective study comprising about 28 000 females reported that CRP is a better predictor of the risk of cardiovascular events than LDL-C [13]. The implication of this and many other supporting studies is profound, and CRP may be used to screen patients with atherosclerosis and its associated clinical syndromes. It has been advocated to measure CRP for CVD risk assessment [6]. However, the current "reference intervals" of CRP have been derived almost exclusively from European or European American reference populations, and its applicability to other populations is unclear, so before advocating the widespread use of CRP as a screening test for individuals who are at risk for CVD, the AHA/CDC in their scientific statement called for information on population-based CRP generated from blacks, Hispanics, Native Americans, and people of Asian and South Asian heritage [14]. There were few studies on distribution of CRP in a representative Chinese population. Table 4 presents the medians of the CRP levels among Chinese reported in different studies [15-21]. However, among these studies, only X. Ye et al and we reported CRP levels in a random sample. And X. Ye et al investigated the distribution of CRP levels only in middle-aged and older Chinese people, and they didn't provide the data of young adults and the detailed distribution of CRP [17]. The differences were not substantial among these reports and most of the studies reported that the median of CRP levels was lower than $1 \mathrm{mg} / \mathrm{L}$ except for Y. Bao's report [19]. Here, we investigated the distribution of CRP in a representative Chinese population including young, middle-aged and older people, and provided data for a wide range of CRP values and the precise relationship between elevated CRP and the traditional cardiovascular risk factors.

The distribution of CRP in adult Chinese was comparable with that of many other Asian populations but different from that of Western populations. The median of CRP reported here was near to that reported in previous studies in other Asian countries. Median $\mathrm{CRP}$ values were $0.60 \mathrm{mg} / \mathrm{L}$ for males and $0.40 \mathrm{mg} / \mathrm{L}$ for females in Koreans aged 16-64 years [22], and 0.6 $\mathrm{mg} / \mathrm{L}$ for males and $0.45 \mathrm{mg} / \mathrm{L}$ for females in Japanese aged more than 40 years [23]. These levels of CRP are quite low and are approximately one third to half of the median values in Caucasians [24,25]. In multiethnic population studies, the CRP levels of Chinese were significantly lower than those of Caucasian populations $[10,26]$. The reason why most Asians have significantly lower CRP levels than Western populations is unclear. Relatively low BMI, genetic diversity and other factors such as diet and lifestyle may influence the CRP levels [27,28].

Our study reported that CRP levels were higher in males than in females, just as many but not all studies in Asian reported [22,23]. One plausible explanation for higher CRP levels in males may be that traditional risk factors of CVD levels were higher in males than in females just as mentioned above. However, the impacts of genders attenuated remarkably after adjusting for other potential factors. It was also reported that no significant difference in the CRP levels between males and females in Chinese [17]. In Western countries, however, conflicting reports existed which reported that 
higher CRP levels were in females than in males [24, 29]. Many factors, such as BMI, lifestyle factors, blood pressure, hormone replacement therapy use, and so on, may influence the relationship between gender [4,24]. More studies are needed to investigate the gender difference of CRP levels.

In line with the results from other populations, there was a linear increase in CRP levels as age increased [24, 30]. These results were consistent with those reported for apparently health adult populations in Western countries and Asian countries. The median CRP of the participants aged 70-80 years was 2.3-fold higher compared with those in the group of 18-30 years. We also found that CRP levels were higher in individuals living in urban than in rural regions just as that reported in Asians [17,23]. The reason for the difference in CRP levels based on location is not entirely clear in our investigation. It may be attributed to the higher prevalence of the metabolic syndrome and overweight in urban than in rural residents in Chinese [31].

Only 1 in 8 participants showed CRP $>3.0 \mathrm{mg} / \mathrm{L}$ in this study population. The proportion of CRP $>$ $3.0 \mathrm{mg} / \mathrm{L}$ was very low, just as a report in Japanese [23]. However, in Western countries, about 1 in 4 males and females showed CRP $>3.0 \mathrm{mg} / \mathrm{L}$ [24]. About 55\% Americans were classified as "high-risk" by using the cutoff values proposed by AHA/CDC compared with only $6 \%$ of Chinese [14]. Most of people with CVD, diabetes or hypertension were treated which may modify CRP levels; however, when they were excluded, the CRP levels were still very low and didn't increase. So the medication wouldn't modify the conclusion of our study greatly. This further indicated that people with CVD, diabetes or hypertension had high CRP levels. Even the participants with CVD history, diabetes, hypertension or those with CRP $>10 \mathrm{mg} / \mathrm{L}$ were excluded; the CRP levels remained very low. So using this cutoff point in Chinese is not appropriate. In this study, we used the top 15th percentile of CRP levels (CRP $\geqslant$ $2.09 \mathrm{mg} / \mathrm{l}$ ) to define elevated CRP in our analysis.

CRP was positively associated with age, BMI, total cholesterol, LDL-C, triglycerides and glucose, and negatively with HDL-C, which in line with other studies $[23,32]$. Elevated CRP was also positively associated with obesity, hypertension, diabetes, high triglycerides, and low HDL-C. These factors are features of metabolic syndrome. Increasing evidence indicated that metabolic syndrome was an important risk factor for CVD incidence [33,34], while CRP levels were associated with the individual metabolic syndrome features and metabolic syndrome itself $[35,36]$. Our re- sults reconfirmed the fact that CRP was a good marker representing an elevated risk of metabolic impairment.

Whether high LDL-C was related to elevated CRP is controversial. It was reported that CRP related to LDL-C neither in males nor in females [23]. Arena $\mathrm{R}$ et al reported that CRP correlated with LDL-C only in females [37], while Lao XQ et al reported that the association between LDL-C and CRP was of borderline significant in males and not significant in females [30]. However, in the current study, we found borderline and abnormal LDL-C increased the prevalence of elevated CRP, which was consistent with other studies $[4,35]$.

We didn't find alcohol consumption was associated with elevated CRP, just as many studies reported [36, 37]. It was reported that smoking was related to higher CRP [29,40], and there were also studies that reported the association was only in males $[23,24]$. In our study, more males smoked; however, we didn't find the relationship in the current study. The reason for the discrepancy between our study and others is not entirely clear, and it may be due to the differences in population characteristics.

Admittedly, with the cross-sectional nature, it is impossible to establish a cause-effect relationship between CRP levels and CVD risk factors. Hence, the ORs should be viewed as measures of association under the appropriate inference. Another potential concern is that CRP, HDL-C, LDL-C, triglyceride and blood glucose levels were measured only once, which might have led to random errors and may not reflect fluctuation over time. CVD history and hypertension were self-reported and what medicine the participants had taken, was not investigated, which are also potential limitations. Besides, we didn't assess female hormone use in the present study. Though it was reported that females with hormone replacement therapy had higher CRP levels than those without [18], we found the levels of CRP were higher in males than in females in this study, so we believe the effect of hormone replacement therapy could be ignored in Chinese adults just as a report in Japanese population [23].

In conclusion, the study is a large-scale, populationbased study to investigate the distribution of CRP and associated traditional cardiovascular risk factors in a Chinese population which represents a wide range of young, middle-aged and older people. So the findings can be generalized to the general population of Chinese adults and the data can be used by Asian public officials for the development of risk CRP definition. The overall CRP levels in both genders were low, and the distribution of CRP was comparable with that of 
many other Asian populations but different from that of Western populations. There was a positive association between elevated CRP levels and feathers of metabolic syndrome including obesity, hypertension, diabetes, low HDL-C and high triglycerides, as well as high LDL-C. These findings suggest that metabolic impairment is associated with a systemic inflammatory response, and CRP levels should be interpreted in conjunction with the lipid profile. Prospective studies on the association of CVD risk factors with CRP levels are needed in China so that a Chinese-specific CRP cutoff point for CVD risk assessment can be identified.

\section{Acknowledgments}

The study was supported by grants from AstraZeneca R\&D, Mölndal, Sweden, and we declare that we have no any conflicts of interests. We gratefully acknowledge Shanghai CDC, Hongkou CDC and Baoshan CDC for their assistance in designing the study, selecting participants and field work. We also thank the respondents who gave their time and effort to participate in the study.

\section{References}

[1] L.G. Futterman and L. Lemberg, Fifty percent of patients with coronary artery disease do not have any of the conventional risk factors, Am J Crit Care 7 (1998), 240-244.

[2] E. Braunwald, Cardiovascular medicine at the turn of the millennium: triumphs, concerns, and opportunities, $N$ Engl J Med 337 (1997), 1360-1369.

[3] R. Ross, Atherosclerosis - an inflammatory disease, N Engl J Med 340 (1999), 115-126.

[4] M.L. Yen, C.Y. Yang, B.L. Yen, Y.L. Ho, W.C. Cheng and C.H. Bai, Increased high sensitivity C-reactive protein and neutrophil count are related to increased standard cardiovascular risk factors in healthy Chinese men, Int J Cardiol 110 (2006), 191-198.

[5] M. Miller, M. Zhan and S. Havas, High attributable risk of elevated C-reactive protein level to conventional coronary heart disease risk factors: the Third National Health and Nutrition Examination Survey, Arch Intern Med 165 (2005), 2063-2068.

[6] M.H. Shishehbor, D.L. Bhatt and E.J. Topol, Using C-reactive protein to assess cardiovascular disease risk, Cleve Clin J Med 70 (2003), 634-640.

[7] T.A. Pearson, G.A. Mensah, R.W. Alexander, J.L. Anderson, R.O. Cannon 3rd, M. Criqui, Y.Y. Fadl, S.P. Fortmann, Y. Hong, G.L. Myers, N. Rifai, S.C. Smith Jr, K. Taubert and R.P. Tracy, F. Vinicor; Centers for Disease Control and Prevention; American Heart Association, Markers of inflammation and cardiovascular disease: application to clinical and public health practice: a statement for healthcare professionals from the Centers for Disease Control and Prevention and the American Heart Association, Circulation 107 (2003), 499-511.
[8] A. Khera, D.K. McGuire, S.A. Murphy, H.G. Stanek, S.R. Das, W. Vongpatanasin, F.H. Wians, Jr., S.M. Grundy and J.A. de Lemos, Race and gender differences in C-reactive protein levels, J Am Coll Cardiol 46 (2005), 464-469.

[9] A. Kelley-Hedgepeth, D.M. Lloyd-Jones, A. Colvin, K.A. Matthews, J. Johnston, M.R. Sowers, B. Sternfeld, R.C. Pasternak, C.U. Chae and SWAN Investigators, Ethnic differences in C-reactive protein concentrations, Clin Chem 54 (2008), 1027-1037.

[10] K.A. Matthews, M.F. Sowers, C.A. Derby, E. Stein, H. Miracle-McMahill, S.L. Crawford and R.C. Pasternak, Ethnic differences in cardiovascular risk factor burden among middleaged women: Study of Women's Health Across the Nation (SWAN), Am Heart J 149 (2005), 1066-1073.

[11] Y.F. Wu, D. Zhao, B.F. Zhou, W. Wang, X. Li, J. Liu, Y. Li, J.Y. Sun, L.C. Zhao, Z.S. Wu and J.R. Zhu, Cut offs and risk stratification of dyslipidemia in Chinese adults, Zhonghua Xin Xue Guan Bing Za Zhi 35 (2007), 428-433.

[12] Z. Bei-Fan, Predictive values of body mass index and waist circumference for risk factors of certain related diseases in Chinese adults: study on optimal cut-off points of body mass index and waist circumference in Chinese adults, Asia Pac $J$ Clin Nutr 11 (2002), S685-S693.

[13] P.M. Ridker, N. Rifai, L. Rose, J.E. Buring and N.R. Cook, Comparison of C-reactive protein and low-density lipoprotein cholesterol levels in the prediction of first cardiovascular events, N Engl J Med 347 (2002), 1557-1565.

[14] T.A. Pearson, T.L. Bazzarre, S.R. Daniels, J.M. Fair, S.P. Formann, B.A. Franklin, L.B. Goldstein, Y. Hong, G.A. Mensah, J.F. Sallis Jr., S. Smith Jr., N.J. Stone, K.A. Taubert and American Heart Association Expert Panel on Population and Prevention Science, American Heart Association guide for improving cardiovascular health at the community level: a statement for public health practitioners, healthcare providers, and health policy makers from the Am Heart Association Expert Panel on Population and Prevention Science, Circulation 107 (2003), 645-651.

[15] B. Yuan, H. Zhang, J. Zou and D. Wang, Distribution of Creactive protein in health adults, Lin Chuang Jian Yan Za Zhi 23 (2005), 236-237.

[16] Q. Dong, D. Yang, H. Ye, J. Fang and Y. Zhang, Distributions of C-reactive Protein and Association with Lipid in 579 Healthy Volunteers, Chin J Hemor 26 (2006), 444-446.

[17] X. Ye, Z. Yu, H. Li, O.H. Franco, Y. Liu and X. Lin, Distributions of C-reactive protein and its association with metabolic syndrome in middle-aged and older Chinese people, J Am Coll Cardiol 49 (2007), 1798-1805.

[18] J. Sun, D. Zhao, W. Wang, J. Liu, J. Cheng, J. Liu, Y. Li and Y. Jia, Distributions of high-sensitivity C-reactive protein and its association with metabolic syndrome in population aged 45-74 in Bering, Chin J Epidemiol 28 (2007), 1155-1158.

[19] Q. Bao, W. Jia, L. Chen, J. Lu and K. Xiang, Association between C-reactive protein level and metabolic syndrome and components thereof, Natl Med J China 86 (2006), 2105-2109.

[20] H. Song, Expression of serum high sensitive $C$ reactive protein in high low-density lipoprotein cholesterol patient, Chin J Med Writing 11 (2004), 561-562.

[21] S. He, Y. Zhuang and L. Chen, Establishing the reference range of high-sensitivity C-reactive protein measurements in 506 healthy adults in Shenzhen area, Chin J Misdiagn 4 (2004), 836-838.

[22] E.Y. Choi, E.H. Park, Y.S. Cheong, I. Rheem, S.G. Park and S. Yoo, Association of C-reactive protein with the metabolic risk 
factors among young and middle-aged Koreans, Metabolism 55 (2006), 415-421.

[23] I. Saito, S. Sato, M. Nakamura, Y. Kokubo, T. Mannami, H Adachi, M. Konishi, K. Okada, H. Iso, K. Kario, F. Ohsuzu, Y. Momiyama and $\mathrm{M}$. Tsushima, A low level of C-reactive protein in Japanese adults and its association with cardiovascular risk factors: the Japan NCVC-Collaborative Inflammation Cohort (JNIC) study, Atherosclerosis 194 (2007), 238-244.

[24] J. Hung, M.W. Knuiman, M.L. Divitini, T. Davis and J.P. Beilby, Prevalence and risk factor correlates of elevated C-reactive protein in an adult Australian population, Am J Cardiol 101 (2008), 193-198.

[25] J. Danesh, J.G. Wheeler, G.M. Hirschfield, S. Eda, G. Eiriksdottir, A. Rumley, G.D. Lowe, M.B. Pepys and V. Gudnason, C-reactive protein and other circulating markers of inflammation in the prediction of coronary heart disease, $N$ Engl J Med 350 (2004), 1387-1397.

[26] S. Anand S., F. Razak, Q. Yi, B. Davis, R. Jacobs, V. Vuksan, E. Lonn, K. Teo, M. McQueen and S. Yusuf, C-reactive protein as a screening test for cardiovascular risk in a multiethnic population, Arterioscler Thromb Vasc Biol 24 (2004), 15091515 .

[27] T.B. Ledue and N, Rifai, Preanalytic and analytic sources of variations in C-reactive protein measurement: implications for cardiovascular disease risk assessment, Clin Chem 49 (2003), $1258-1271$.

[28] A.J. MacGregor, J.R. Gallimore, T.D. Spector and M.B. Pepys, Genetic effects on baseline values of C-reactive protein and serum amyloid A protein: a comparison of monozygotic and dizygotic twins, Clin Chem 50 (2004), 130-134.

[29] X. Zhang, X.O. Shu, L.B. Signorello, M.K. Hargreaves, Q. Cai, M.F. Linton, S. Fazio, W. Zheng and W.J. Blot, Correlates of high serum C-reactive protein levels in a socioeconomically disadvantaged population, Dis Markers 24 (2008), 351-359.

[30] X.Q. Lao, G.N. Thomas, C.Q. Jiang, W.S. Zhang, P. Yin, P. Adab, T.H. Lam and K.K. Cheng, C-reactive protein and the metabolic syndrome in older Chinese: Guangzhou Biobank Cohort Study, Atherosclerosis 194 (2007), 483-489.

[31] D. Gu, K. Reynolds, X. Wu, J. Chen, X. Duan, R.F. Reynolds, P.K. Whelton, J. He and InterASIA Collaborative Group, Prevalence of the metabolic syndrome and overweight among adults in China, Lancet 365 (2005), 1398-1405.
[32] J.S. Yudkin, C.D. Stehouwer, J.J. Emeis and S.W. Coppack, C-reactive protein in healthy participants: associations with obesity, insulin resistance, and endothelial dysfunction: a potential role for cytokines originating from adipose tissue? Arterioscler Thromb Vasc Biol 19 (1999), 972-978.

[33] A. Galassi, K. Reynolds and J. He, Metabolic syndrome and risk of cardiovascular disease: a meta-analysis, Am J Med 119 (2006), 812-819.

[34] Y. He, B. Jiang, J. Wang, K. Feng, Q. Chang, L. Fan, X. Li and F.B. Hu, Prevalence of the metabolic syndrome and its relation to cardiovascular disease in an elderly Chinese population, $J$ Am Coll Cardiol 47 (2006), 1588-1594.

[35] S. Lim, H.K. Lee, K.C. Kimm, C. Park, C. Shin and N.H. Cho, C-reactive protein level as an independent risk factor of metabolic syndrome in the Korean population. CRP as risk factor of metabolic syndrome, Diabetes Res Clin Pract $\mathbf{7 0}$ (2005), 126-133.

[36] E.S. Ford, W.H. Giles, A.H. Mokdad and G.L. Myers, Distribution and correlates of C-reactive protein concentrations among adult US women, Clin Chem 50 (2004), 574-581.

[37] M. Raitakari, K. Mansikkaniemi, J. Marniemi, J.S. Viikari and O.T. Raitakari, Distribution and determinants of serum highsensitive C-reactive protein in a population of young adults: The Cardiovascular Risk in Young Finns Study, J Intern Med 258 (2005), 428-434.

[38] M.A. Martínez, J.G. Puig, M. Mora, R. Aragón, P. O’Dogherty, J.L. Antón, T. Sánchez-Villares, J.M. Rubio, J. Rosado, R. Torres, J. Marcos, L.F. Pallardo, J.R. Banegas and MAPA (Monitorización Ambulatoria de la Presión Arterial) Working Group, Metabolic syndrome: prevalence, associated factors, and C-reactive protein: the MADRIC (MADrid RIesgo Cardiovascular) Study,Metabolism 57 (2008), 1232-1240.

[39] R. Arena, J.A. Arrowood, D.Y. Fei, S. Helm and K.A. Kraft, The relationship between C-reactive protein and other cardiovascular risk factors in men and women, J Cardiopulm Rehabil 26 (2006), 323-327.

[40] J. O'Loughlin, M. Lambert, I. Karp, J. McGrath, K. GrayDonald, T.A. Barnett, E.E. Delvin, E. Levy and G. Paradis, Association between cigarette smoking and C-reactive protein in a representative, population-based sample of adolescents, Nicotine Tob Res 10 (2008), 525-532. 


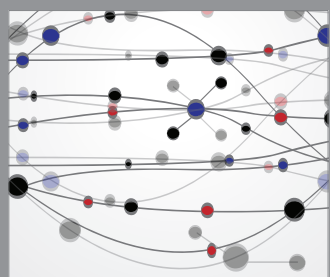

The Scientific World Journal
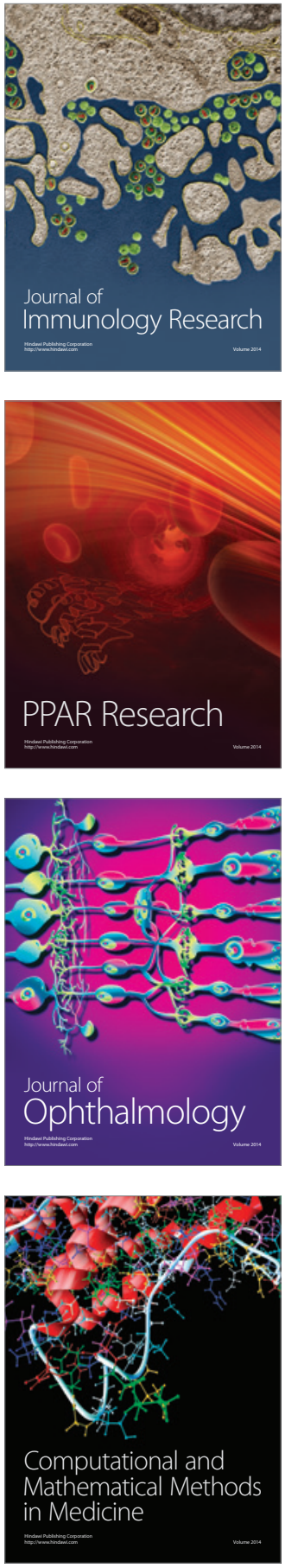

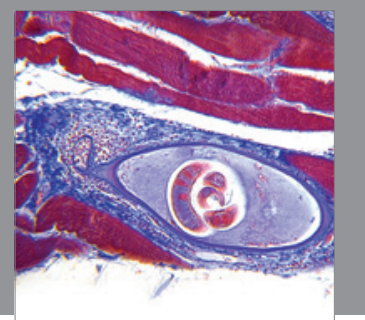

Gastroenterology

Research and Practice
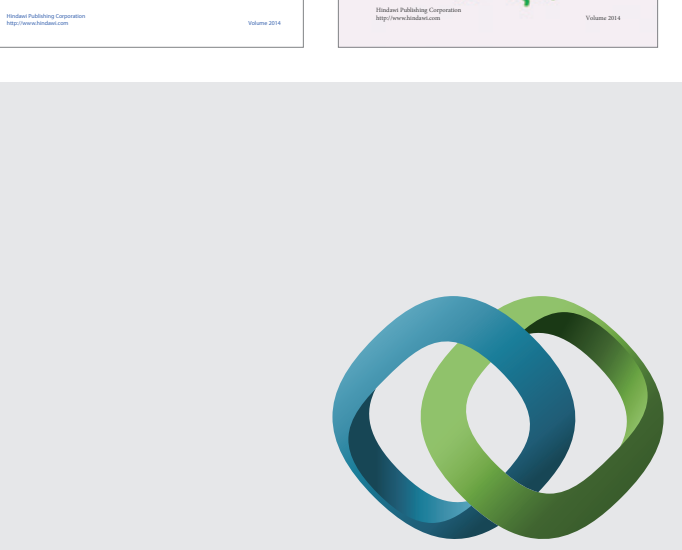

\section{Hindawi}

Submit your manuscripts at

http://www.hindawi.com
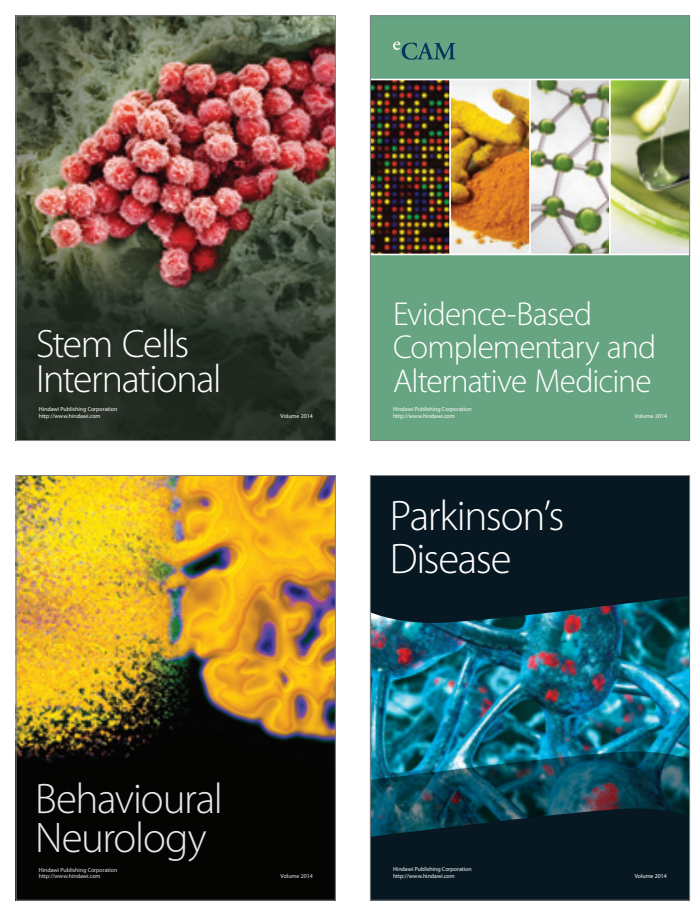

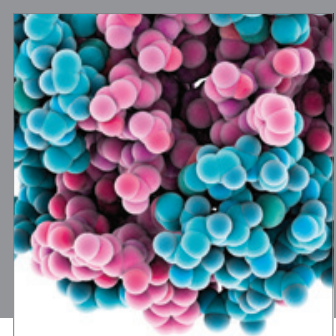

Journal of
Diabetes Research

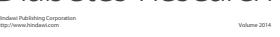

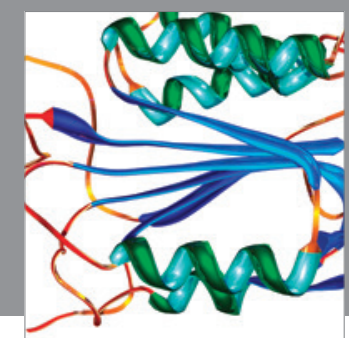

Disease Markers
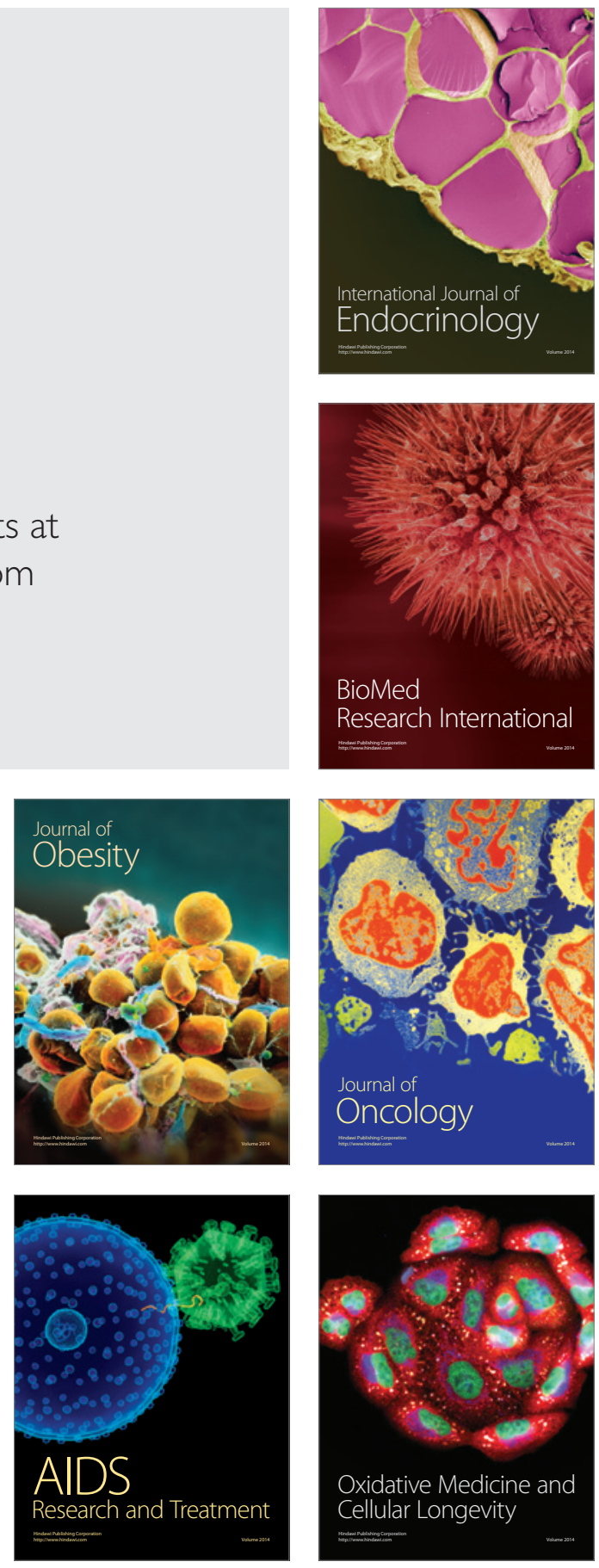